\title{
The Design Of Colleges And Universities Education Resource Platform Based On Cloud Computing
}

\author{
Guoxia Zou \\ Department of Engineering Technology,Guangdong Polytechnic Institute,Guangdong,China \\ zouguoxia@163.com
}

Keywords: Cloud Computing; Middleware; Education Resources.

\begin{abstract}
With the rapid growth of colleges and universities education resources, people more frequently access to those resources on the network, but the distribution of resources is too loose and the repeat of resources is too high, people need a lot of time to get information from those resources and constantly jump from one site to another for some information. According to this situation, this paper designed a system of colleges and universities education resource based on cloud computing. With this system, people get resources do not need to find everywhere, people can directly find all of the educational resources on the system platform, it not only save a lot of time, but also save the brain; With this system, resource managers or information publishers can pass the information in the shortest time, eliminating the need for duplication of labor.
\end{abstract}

\section{Introduction}

With the rapid development of information technology, network technology and communication technology, Colleges and Universities education resources are becoming more and more abundant, many Colleges and Universities have produced some quality courses, many big website appeared MOOC course. In order to promote the teachers to master the latest information technology to hold all kinds of competitions, such as the micro lesson competition, the information technology teaching competition, etc. Education resources in colleges and universities is expansive growth, therefore, when you need to find and collect information, the information is too big, need to spend a lot of time to differentiation and filter.

The higher authorities cascaded down issued a notice, when the notice come to school, the end date is approaching, so teachers are in a hurry to execution notice.

When people want to apply postgraduate or doctoral exam, they need to find the school first, and then find The graduate department, and then find whether there is a recruit professional, that bother people very much.

All the above problems, is due to large amount of information, and the information is not concentrate, and there is no convenient tool to filter the information. With the emergence of cloud computing, it can convenient the scattered resources by the network to form a shared pool of resources, then based on shared resource pool, to realize the resources classification and on-demand lookup.

\section{Cloud Computing Applications In The Field Of Education}

Cloud computing applications in the field of education is called Educational cloud,it includes Cloud Computing Assisted Instructions (CAIC) and Clouds Computing Based Education(CCBE $)^{[1-6]}$.

CCAI means that the school and teachers using education cloud services supported by the cloud computing to build personalized teaching information environment. It Supports teacher's effective teaching and students' active learning, promotes the students' advanced thinking ability and swarm intelligence development, improves the quality of education.

CCBE means that, In various fields of education, using cloud computing services to assist the education teaching activities. CCBE is a new discipline concept, belongs to the cross field of computer science and education science, Mainly to explore the application rule of cloud computing 
services in the education teaching, Studies education teaching resources and the process of design and management based on The dominant theory of learning.

This paper is concerned with the integration of college education resources based on cloud computing to provide a convenient platform for teachers and students.

\section{Platform Design}

Because of educational resources are too rich,the user of educational resources are to much, and education platform should follow the characteristics of education. This article only pays attention to the public part of the Colleges and universities education resources, the private education resources of Colleges and universities not included in the platform ${ }^{[7-10]}$.

This paper designed system running environment and System composition, which is divided into three parts, they are information platform construction, the overall framework of the Colleges and Universities education resource system, and system platform module of colleges and universities education resource. The following are described.

\subsection{Information Platform Construction.}

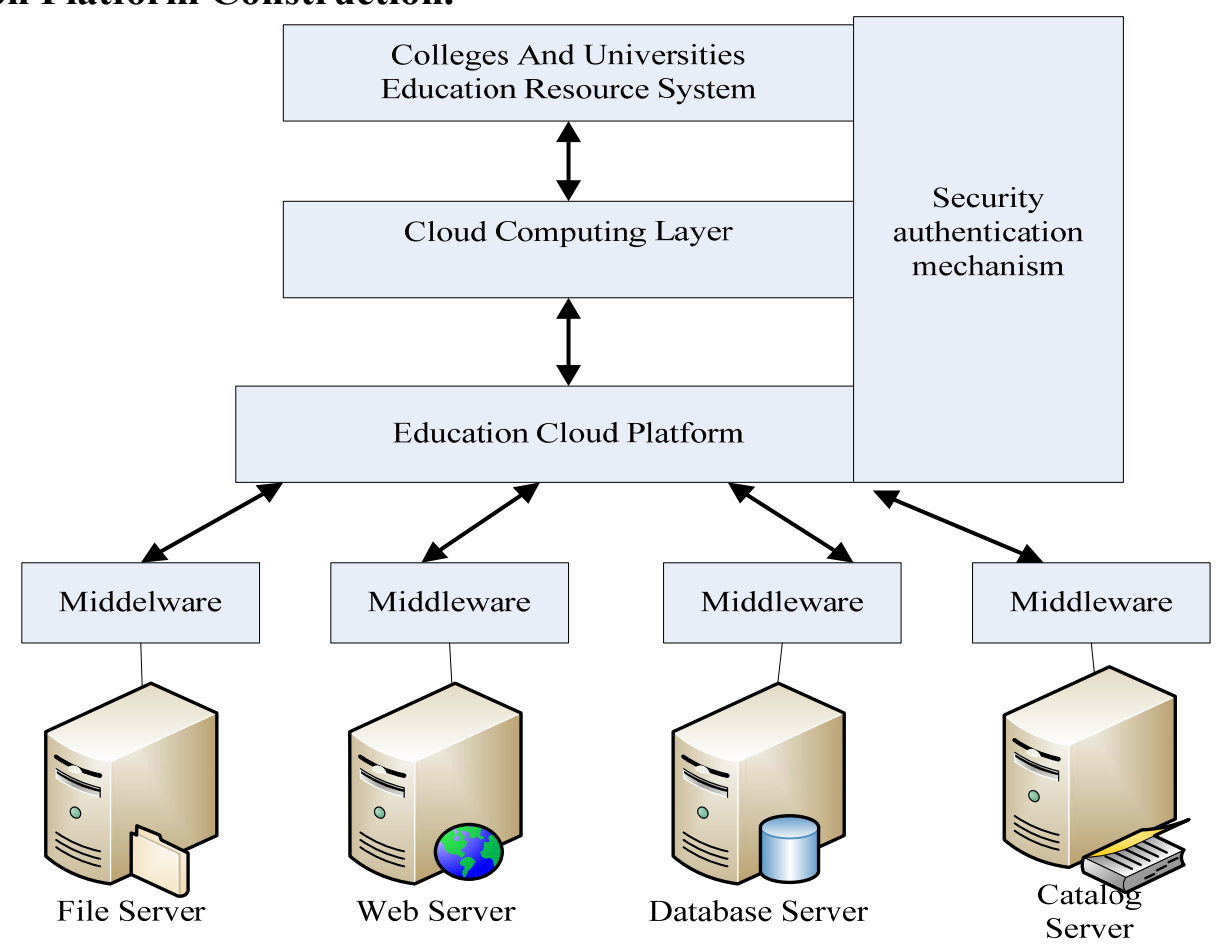

Figure1. Information platform construction

Cloud computing layer: mainly used to calculate the location of resources, balance network load, allocate resources

Education cloud platform: the hardware resource platform of cloud computing

Middleware: Shield inconsistent of the database server, the operating system and the file system

Security authentication mechanism: the combination of cloud computing authentication mechanism (Keystone), from the users login to the system to access the cloud platform, in the whole process, every step of the resource access requires authentication. To ensure the security of information and correctness, and non-repudiation.

\subsection{The Overall Framework Of The Colleges And Universities Education Resource System}

Colleges and universities education resources system is composed of three kinds of users: ordinary users, system users, cloud client users. As shown in Figure 2.

Ordinary users: Users can be students, teachers and other people, do not need to be certified, they access to the system with the web browser, they can browse resources, download resources.

System users: This user has only a few people, they have the ability to manage and monitor the whole system, such as the platform service directory configuration, adding and deleting a user, etc. 
Cloud client users: the users are mainly the platform management of colleges and universities, education administrative department of colleges and universities. They use the web browser or web application to access the platform to publish information and manage the resources, If a publishing information needed to multistage audit, When information release, it automatically transfer to superior for approval, When all the approval is completed, the information can be presented in the web client.

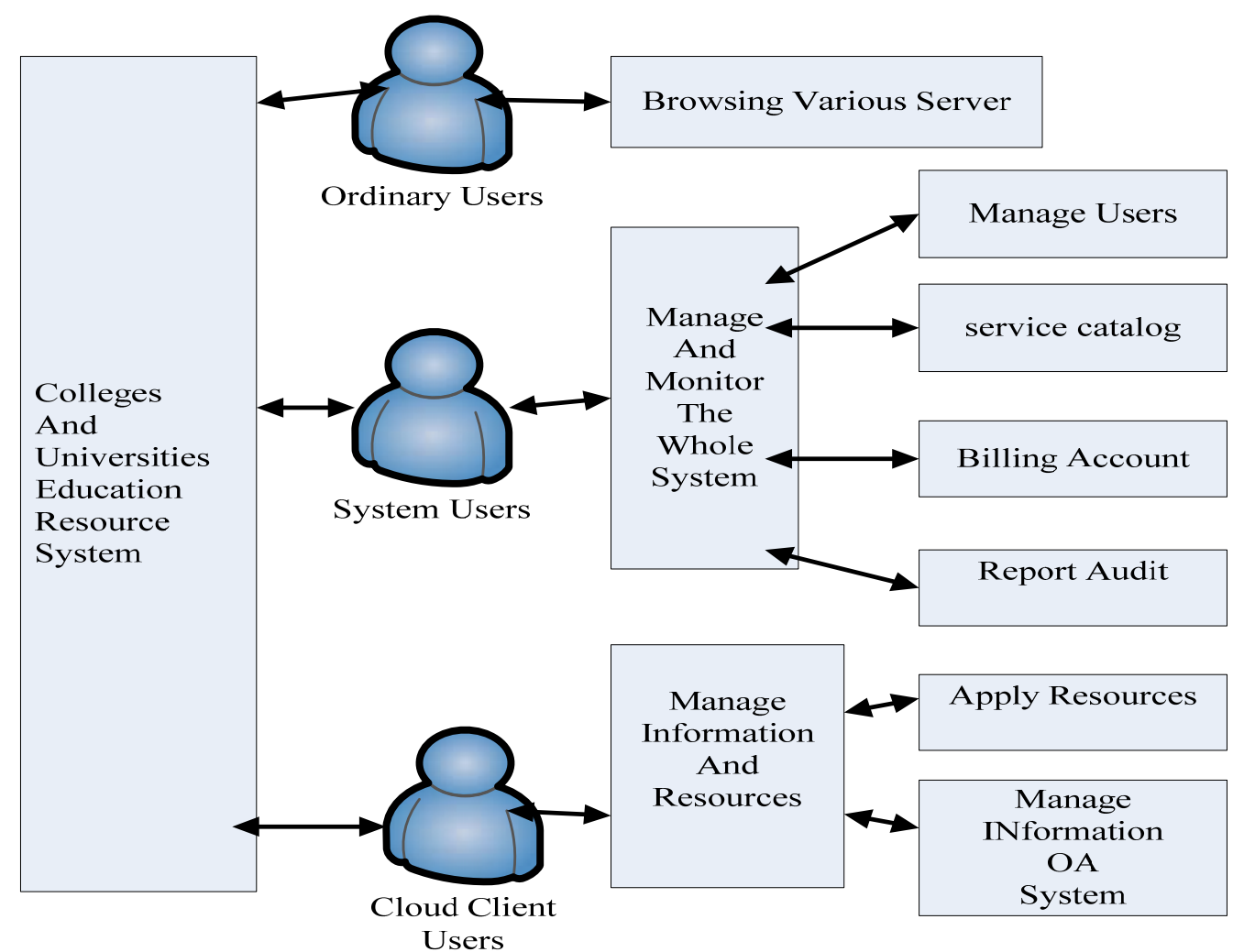

Figure2. The Overall Framework Of The Colleges And Universities Education Resource System

\subsection{The Design On System Platform Module Of Colleges And Universities Education Resource .}

In Colleges and universities, the school mainly attaches to scientific research, competition, policy news, propaganda, enrollment; teachers are keen to focus on research, competition, policy news; students pay attention to the course, enrollment information. Around these aspects, the system module of the college education resource as shown in figure 3.

If the higher authorities publish scientific research, competition, news and other information, there is no need to issued the information to every school, then the school load the information on their official website. The higher authorities can directly publish the information on the platform ,then all the schools can bower the information. With this platform, Message passed with the fastest speed.

With this platform, students and teachers can be very conveniently to find the courses they want to learn, they can easily find enrollment information to prepare for further education. 


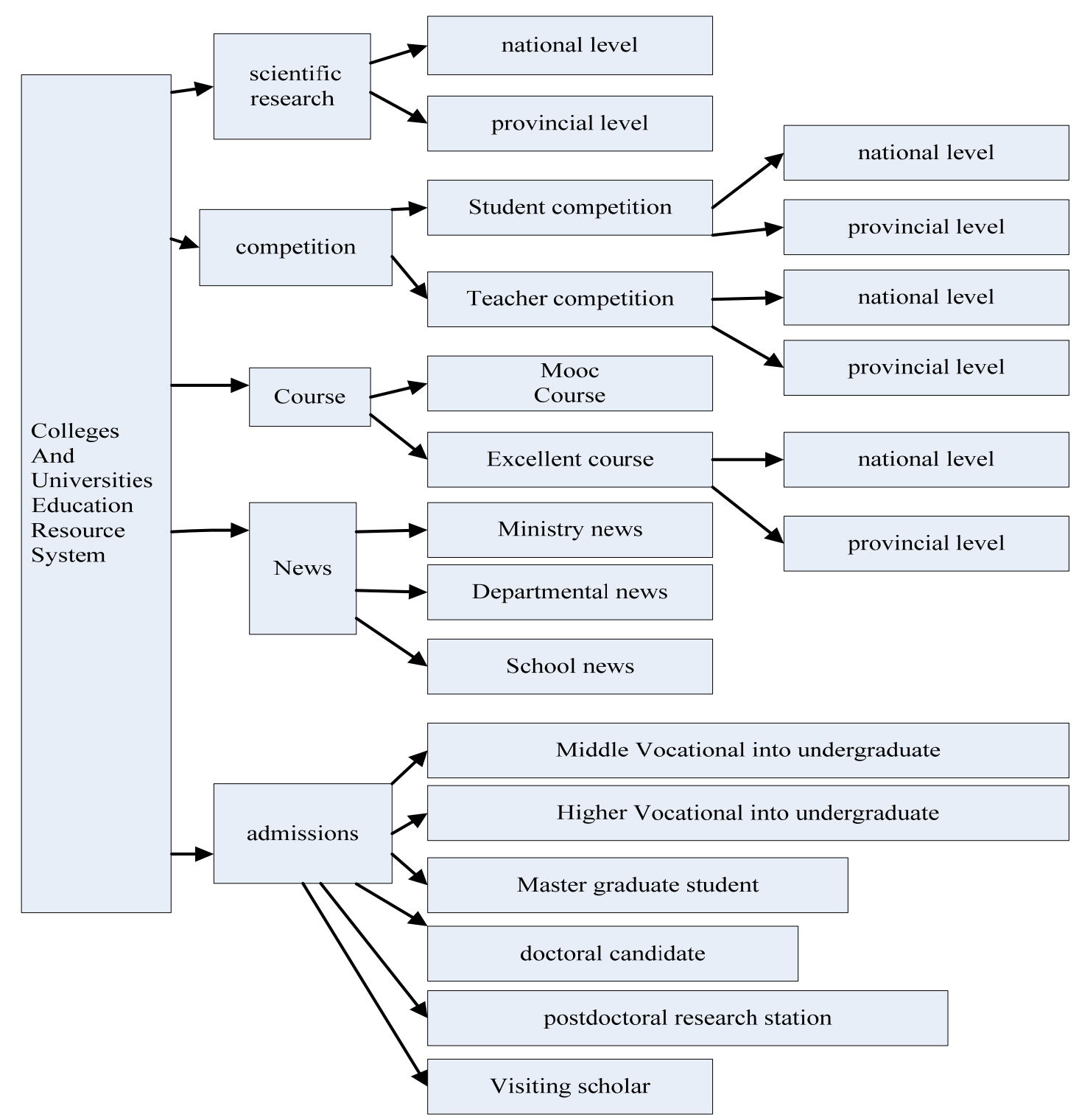

Figure3. System Platform Module of Colleges and Universities Education Resource .

Scientific research module:it is divided into national level and provincial level, national research institutions directly send the information to the platform, then all provinces, all teachers and researchers can see; Provincial scientific research institutions directly send the information to the platform, then all schools, all teachers and researchers can see. On the platform you can also know that other schools or research institutions are studying in which field, it is conducive to information sharing, and avoiding plagiarism.

Competition module: it is divided into student competiton and teacher competion. For students, the ability of the students could not have been discoveried and excavated by the teacher, students best know themselves, but students lack of competition information.If students use this platform, they can immediately get their interested competition, ahead of time to prepare for the work. For the teacher, the competition information comes from the school related departments to publish the information, if the relevant departments do not have the first time to obtain information, or information can not be released in time, the teacher would not be enough time to paraper the competition. The result is that the teacher is not satisfied with the results of the competition, it will influence teacher's enthusiasm.If teachers use this platform, they can obtain information immediately, and make full preparations to improve the quality of the competition.

Course modules: with the development of information, the teacher and the students need to continue to learn, This platform collects curriculum quality resources, to eliminat the time for teachers and students to find resources. Teachers and students can better plan their own learning plan by the concentration of resources. 
News module: when school won prizes such as news, the school will announce the news on its official website, to praise the award-winning teacher, at the same time, encourage other teachers to progress. Through this platform, the message can be maximize propaganda.Once the news release, all school teachers can see.

Admissions module: in order to adapt higher vocational education connect with the middle vocational, undergraduate education connect with the higher vocational, the platform collect all admission policy, the student can learn about admissions policy in advance on this platform, determine their own learning plan. Students make their own planning more accurate and more specific with the centralized and the integrated information resources.

\section{Summary}

This paper designed a platform, which is divided into three parts, they are information platform construction, the overall framework of the colleges and universities education resource system, and system platform module of colleges and universities education resource. Information platform construction is that education cloud platforms integrates the various information systems by middleware; the overall framework of colleges and universities education resource system is designed for user, the system platform module of colleges and universities education resource is designed for the functional of system. It is discussed on the system platform that the user convinence and platform benefit, this paper. If the designed system can be implemented, it will bring a lot of benefits for the management department, school, teacher and scientific research departments and the students .

\section{Acknowledgment}

I am grateful to Guangdong Polytechnic Institute, and The Open University of Guangdong. They give me much support to study cloud computing field, and provided a project for me, the number of the project is 1308 .

\section{References}

[1] Caifeng Zou,Huifang Deng, and Qunye Qiu, Design and Implementation of Hybrid Cloud Computing Architecture Based on Cloud Bus, 2013 IEEE Ninth International Conference on Mobile Ad-hoc and Sensor Networks (MSN), 2013,pp:289-293.

[2] Junggab Son, Hussain, R., Hunmin Kim, Heekuck Oh, SC-DVR: a secure cloud computing based framework for DVR service ,2014 IEEE Transactions on Consumer Electronics,2014, Volume: 60, Issue: 3 ,Pages: $368-374$.

[3] Zhuang $\mathrm{Wu}$, Study and realization of automatic supply solution for enterprise IT basic facility based on cloud computing,World Automation Congress (WAC), 2012 ,Pages: 1 - 4 .

[4] Zhidong Shen, Li Li, Fei Yan, Xiaoping Wu, Cloud Computing System Based on Trusted Computing Platform ,Intelligent Computation Technology and Automation (ICICTA), 2010 International Conference on ,Year: 2010, Volume: 1 ,Pages: 942 - 945.

[5] Cui Yun-fei, Li Yi, Zhu Ji-lu, Wang Peng, The research on cloud computing architecture for campus-based networks, 2013 IEEE Conference on Anthology, 2013,Pages: 1 - 4.

[6] Haijun Gu, Yufeng Diao, Wei Liu, Xueqian Zhang, The design of smart home platform based on Cloud Computing,Electronic and Mechanical Engineering and Information Technology (EMEIT), 2011 International Conference on ,Year: 2011, Volume: 8 ,Pages: 3919 - 3922.

[7] Pei Hongluo,Wang Yunsheng,Jiang Hongtao,Cheng Binbin, Yao Ligen ,Architecture Design of Digital Library Platform Base on Cloud Computing,Journal of Agricultural Science and Technology, 2010,12(6):126-129. 
[8] XIAO Suyong,WU Limin,LIU Wenjun, Cloud Computing Based Geographic Information Public Service Platform:Application and Research, Bulletin of Surveying and Mapping,2012,9:78-80.

[9] Yang Y i ng, Rese rch a ou t Construction and Sharing Digital Resources of Library In Cloud Computing Environment, Value E ngineering 2010,31:195-196.

[10]Huang Rui,Liu Jianqiao, Construction of teaching resources management system based on cloud computing, Journal of Fuyang Teachers College (Natural Science),Sep.2014,Vol.31, No. $3: 51-54$. 